\title{
A INUNDAÇÃO PELAS MARÉS AFETA PARÂMETROS POPULACIONAIS DO CARANGUEJO-UÇÁ, UCIDES CORDATUS (LINNAEUS, 1763) (BRACHYURA: OCYPODIDAE)?: ESTUDO EM DUAS FEIÇÕES DE MANGUEZAL NA ESTAÇÃO ECOLÓGICA JURÉIA-ITATINS (PERUÍBE, SP).
}

\author{
Pimenta, C.E.R. ${ }^{1,}$; Matsunaga, A.M.F. ${ }^{1}$; João, M.C.A. ${ }^{1}$; Santos, L.C.M. ${ }^{2}$; Masunari,S. ${ }^{3}$ \& Pinheiro, M.A.A $^{1}$ \\ ${ }^{1}$ Universidade Estadual Paulista (UNESP), Instituto de Biociências (IB), Campus Litoral Paulista (CLP), Laboratório de Biologia \\ da Conservação de Crustáceos (LBC/CRUSTA), São Vicente (SP); ${ }^{2}$ Universidade Federal do Paraná (UFPR), Setor de Ciências \\ Biológicas, Departamento de Zoologia, Curitiba (PR); ${ }^{3}$ Instituto Federal de São Paulo (IFSP), Campus Pirituba, São Paulo (SP).
}

*Autor correspondente: camilla.evelyn94@gmail.com

\begin{abstract}
Ucides cordatus (Linnaeus, 1763) é um caranguejo endêmico de manguezais, com elevada abundância e ocorrência por todo o litoral brasileiro. O presente estudo visa confrontar sua densidade e estrutura populacional, numa comparação sazonal (verão e inverno), na ESEC Juréia-Itatins (Peruíbe/SP), em duas feições de manguezal (margem e "apicum"). Em cada uma delas o nível médio de inundação pelas marés (NI) foi obtido pela medida da distribuição vertical máxima das macroalgas (Bostrychietum), na base do tronco de 50 árvores, bem como foram utilizados cinco quadrados amostrais $(5 \times 5 \mathrm{~m})$ para registro dos parâmetros populacionais da espécie: 1 ) densidade (registro do número de galerias/área); e 2) estrutura populacional (medida do diâmetro das galerias ativas convertidas para o tamanho do animal $=$ LC, largura de carapaça). O nível médio de inundação na margem $(27,5 \pm 8,6 \mathrm{~cm})$ foi cerca de seis vezes superior ao do "apicum" $(4,6 \pm 1,7 \mathrm{~cm})\left(t=5,18 ; p=5,3 \cdot 10^{-5}\right)$. No geral, o maior adensamento da espécie ocorreu no "apicum", especialmente no verão $\left(4,9 \pm 2,1 \mathrm{ind} . / \mathrm{m}^{2}\right)$, que foi duas vezes superior ao da margem estuarina $\left(2,8 \pm 0,6\right.$ ind. $\left./ \mathrm{m}^{2}\right)(\mathrm{t}=-2,13 ; \mathrm{p}=0,065)$, embora tenham sido

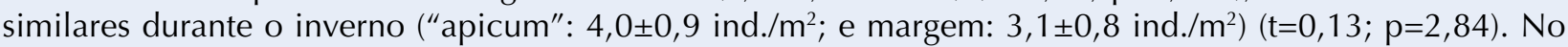
verão o tamanho (LC) dos animais variou de 23,5-89,2 mm $(43,1 \pm 13,7 \mathrm{~mm})(\mathrm{t}=21,19 ; \mathrm{p}=0,000)$, sendo similar ao inverno $(22,2-90,7 \mathrm{~mm} ; 42,2 \pm 12,2 \mathrm{~mm})(\mathrm{t}=17,50 ; \mathrm{p}=0,000)$, embora com caranguejos maiores na margem $(53,5 \pm 14,3 \mathrm{~mm})$ em comparação ao "apicum" (36,6 $\pm 8,9 \mathrm{~mm})$. Durante o verão a estrutura populacional (LC) no "apicum" teve um único grupo modal ( $M 1: 38,3 \pm 7,4 \mathrm{~mm})$, ocorrendo dois na margem (M1: 43,9 $95,4 \mathrm{~mm}$; e M2: $67,0 \pm 10,7 \mathrm{~mm})$, enquanto no inverno ocorreram dois grupos nas duas feições, confirmando animais menores no

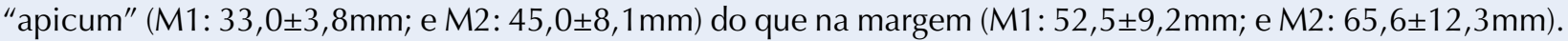
Os resultados evidenciam um recrutamento diferencial e migração do "apicum" para a margem, bem como confirmam variações dos dois parâmetros populacionais em função do nível de inundação. O monitoramento destes parâmetros tem confirmado o prognóstico de alterações climáticas locais e/ou regionais, além de embasar, para o "apicum", sua importância como uma feição de manguezal indicada para a preservação de U. cordatus, devido ao maior adensamento dos indivíduos de menor porte.
\end{abstract}

Palavras-chave: densidade populacional, estrutura populacional, sazonalidade.

Financiamento: FAPESP/FGB (Projeto Uçá-Clima, Proc. n 2014/50438-5; Bolsa IC, Proc. no 2017/03915-0). 